Pesq. Vet. Bras. 36(1):45-54, janeiro 2016 DOI: $10.1590 / \mathrm{S} 0100-736 \mathrm{X} 2016000100008$

\title{
Morfologia da laringe em Cerdocyon thous (Linnaeus, 1766) ${ }^{1}$
}

\author{
Paulo Souza Junior ${ }^{2 *}$, Natan C. Carvalho ${ }^{2}$, Karine Mattos ${ }^{2}$, Bruno L. Anjos ${ }^{3}$ \\ e André L.Q. Santos ${ }^{4}$
}

\begin{abstract}
Souza Junior P., Carvalho N.C., Mattos K., Anjos B.L. \& Santos A.L.Q. 2016. [Laryngeal morphology in Cerdocyon thous (Linnaeus, 1766).] Morfologia da laringe em Cerdocyon thous (Linnaeus, 1766). Pesquisa Veterinária Brasileira 36(1):45-54. Laboratório de Anatomia Animal, Universidade Federal do Pampa, Rodovia BR-472 Km 585, Uruguaiana, RS 97500-970, Brazil.E-mail: paulosouza@unipampa.edu.br

Cerdocyon thous (crab-eating fox) is the most common wild canid in South American territory. The aim of this paper was to describe macroscopic, microscopic and comparative morphology of the larynx of this species. Analyses of larynges of sixteen specimens (four males and twelve females) revealed the topography, conformation, morphometrics, intrinsic muscles and histological characteristics. The larynx was positioned ventral to the axis and comprised one cricoid and one thyroid cartilage (hyaline), one epiglottis (elastic) and a pair of arytenoids (mixed). A pair of sesamoid cartilages was identified between the corniculate processes and the cricoid lamina. Morphometry revealed that thyroid cartilage was the largest. There were no conclusive signs of sexual dimorphism in the larynx of this species. Squamous stratified epithelium predominated and underwent transition to ciliated pseudo-stratified at the level of caudal thyroid and rostral cricoid portions. By comparison, larynx of $C$. thous showed similarity with the domestic dog, although the shape of cartilages has shown some variation.
\end{abstract}

INDEX TERMS: Animal anatomy, crab-eating-fox, Cerdocyon thous, larynx, neotropical canids, wild carnivores.

RESUMO-- Cerdocyon thous (cachorro-do-mato) é o canídeo silvestre mais comum em território sul-americano. Objetivou-se com o presente trabalho descrever a morfologia macroscópica, microscópica e comparada da laringe nesta espécie. Para tal, as laringes de dezesseis espécimes (quatro machos e doze fêmeas) foram analisadas quanto à topografia, forma, morfometria, musculatura intrínseca e histologia. A laringe dispôs-se ventralmente ao áxis e foi constituída por uma cartilagem tireoide e outra cricoide (hialinas), uma epiglótica (elástica) e um par de aritenoides (mistas). Um par de cartilagens sesamoides foi identificado

\footnotetext{
${ }^{1}$ Recebido em 21 de maio de 2015.

Aceito para publicação em 10 de dezembro de 2015.

${ }^{2}$ Laboratório de Anatomia Animal, Universidade Federal do Pampa (Unipampa), Rodovia BR-472 Km 585, Cx. Postal 118, Uruguaiana, RS 9750-970, Brasil. *Autor para correspondência: paulosouza@unipampa. edu.br

${ }^{3}$ Laboratório de Patologia Veterinária, Unipampa, Rodovia BR-472 Km 585, Cx. Postal 118, Uruguaiana, RS 9750-970.

${ }^{4}$ Laboratório de Ensino e Pesquisa em Animais Silvestres (LAPAS), Faculdade de Medicina Veterinária, Universidade Federal de Uberlândia (UFU), Rua Piauí, Bloco 4S, Jardim Umuarama, Uberlândia, MG 38400-902, Brasil.
}

entre os processos corniculados e a lâmina da cricoide. A morfometria revelou que a tireoide é a maior cartilagem. Não houve sinais definitivos de dimorfismo sexual na laringe de $C$. thous. 0 epitélio predominante foi do tipo pavimentoso estratificado o qual sofreu transição para pseudoestratificado cilíndrico ciliado ao nível do terço caudal da tireoide e rostral da cricoide. A laringe de $C$. thous mostrou semelhança com a do cão doméstico, ainda que o formato das cartilagens tenha apresentado diferenças.

TERMOS DE INDEXAÇÃO: Anatomia animal, cachorro-do-mato, Cerdocyon thous, canídeos neotropicais, carnívoros silvestres, cartilagens, laringe.

\section{INTRODUÇÃO}

Cerdocyon thous, conhecido como cachorro-do-mato ou graxaim-do-mato, é o canídeo silvestre com distribuição mais ampla na América do Sul (Cheida et al. 2006, Hunter 2011). Com pelagem cinza-claro e faixa de pelos pretos no dorso, tem massa corporal entre 5 a $9 \mathrm{~kg}$ e pode chegar a $1,2 \mathrm{~m}$ entre a ponta do focinho à cauda (Kasper et al. 2014). Sua dieta é onívora, baseada em frutos, insetos, crustáceos, pequenos vertebrados e ovos (Cheida et al. 2006, Hunter 2011). Habi- 
ta tanto regiões de vegetação aberta quanto fechada (Kasper et al. 2014). As principais ameaças para espécie decorrem da caça por produtores rurais e para obtenção da pele, atropelamentos e doenças transmitidas por cães domésticos (Cheida et al. 2006, Hunter 2011, Kasper et al. 2014).

A laringe é um órgão musculocartilaginoso que conecta a faringe à traqueia (Banks 1991, König \& Liebich 2011). Atua na fonação e previne a broncoaspiração de material estranho (König \& Liebich 2011). 0 conhecimento da anatomia comparada da laringe entre espécies silvestres é importante, pois embasa discussões evolucionistas e funcionais sobre seu papel na respiração e vocalização (Harrison 1995). Além disso, o entendimento da estrutura da laringe é essencial para procedimentos veterinários como intubação endotraqueal e cirurgias corretivas (Monteiro 2013).

Apesar de descrições sobre a forma, disposição e constituição musculocartilaginosa da laringe dos animais domésticos serem encontradas nos livros-texto (Hare 1986, Dyce et al. 2010, König \& Liebich 2011), poucos estudos estabelecem proporcionalidades ou investigam sinais de dimorfismo sexual na laringe de mamíferos domésticos ou silvestres (Tayama et al. 2001, Frey et al. 2007, Wysocki et al. 2008b, Charuta et al. 2009, Wysocki et al. 2010). Quando disponíveis, tais estudos restringem-se à análise de poucos espécimes e não avaliam características morfométricas (Adaro et al. 2004, Oliveira et al. 2011, Bertassoli et al. 2013, Erdoğan \& Pérez 2013). Por outro lado, análises detalhadas da laringe humana já foram bem documentadas (Maue \& Dickson 1971, Eckel et al. 1994).

Diante da relevância da espécie e da ausência de descrições sobre seu aparato respiratório, objetivou-se relatar as características constitutivas, topográficas, macroscópicas, microscópicas e comparadas da laringe do C. thous.

\section{MATERIAL E MÉTODOS}

Obtenção e preparo das laringes. As laringes foram obtidas de dezesseis espécimes de Cerdocyon thous (quatro machos e doze fêmeas) coletados mortos em rodovias da mesorregião sudoeste rio-grandense (autorização IBAMA/SISBIO no 33667). Apenas indivíduos com a dentição permanente foram incluídos. Após recolhimento, os cadáveres foram fixados com injeções subcutâneas, intramusculares e intracavitárias de solução de formaldeído a $50 \%$ e em seguida imersos na mesma solução a $10 \%$. Decorridos sete a catorze dias de fixação, as laringes foram removidas. Para tal, fez-se uma incisão mediana na pele da região cervical ventral, estendendo-se desde o terço médio do pescoço até o espaço intermandibular. Em seguida, removeu-se a fáscia superficial e os músculos extrínsecos foram seccionados ao nível dos seus terços médios. Logo após, secções do aparelho hioideo e transversais dos primeiros anéis traqueais permitiram a retirada do órgão.

Estudo macroscópico, topográfico e morfométrico. Após a remoção da laringe, os cotos de musculatura extrínseca foram excisados, o que possibilitou a dissecação individualizada da musculatura intrínseca. Em seguida, tais músculos foram liberados das suas fixações nas cartilagens laríngeas para que as medições fossem realizadas.

Um paquímetro digital (capacidade $0-150 \mathrm{~mm}$, resolução $0,01 \mathrm{~mm}$, exatidão $\pm 0,02 \mathrm{~mm}$, ZAAS Precision, Amatools ${ }^{\circledR}$ ) foi utilizado para as aferições em duplicata por examinador único. Para que as medições $3 b, 3 c$, 5 b e $5 c$ fossem acuradas, as laringes foram incisadas no plano mediano. As medidas bilaterais (1e, 1f, 1g, 2f,
Quadro 1. Relação e legenda das medições realizadas nas laringes de Cerdocyon thous

\begin{tabular}{|c|c|}
\hline Legenda & Cartilagem tireoide \\
\hline $1 \mathrm{a}$ & Comprimento craniocaudal da lâmina no plano mediano \\
\hline $1 \mathrm{~b}$ & Distância entre os cornos craniais \\
\hline $1 \mathrm{c}$ & Distância entre os cornos caudais \\
\hline $1 \mathrm{~d}$ & Largura máxima ao nível das lâminas \\
\hline $1 \mathrm{e}$ & Comprimento dos cornos rostrais \\
\hline 1f & Comprimento dos cornos caudais \\
\hline $1 \mathrm{~g}$ & Comprimento máximo da cartilagem (do corno rostral ao caudal) \\
\hline $2 \mathrm{a}$ & $\begin{array}{c}\text { Cartilagem cricóide } \\
\text { Largura ao nível do ponto central da art. cricoaritenóidea }\end{array}$ \\
\hline $2 b$ & $\begin{array}{l}\text { Comprimento rostro-caudal do arco da cartilagem cricóide no } \\
\text { plano mediano }\end{array}$ \\
\hline $2 \mathrm{c}$ & Comprimento rostro-caudal da lâmina no plano mediano \\
\hline $2 \mathrm{~d}$ & Comprimento dorso-ventral externo no plano mediano \\
\hline $2 \mathrm{e}$ & Lúmen dorso-ventral no plano mediano \\
\hline $2 \mathrm{f}$ & $\begin{array}{l}\text { Distância do ponto central da art. cricotireoidea até o limite } \\
\text { ventral mediano }\end{array}$ \\
\hline $2 \mathrm{~g}$ & $\begin{array}{l}\text { Distância do ponto central da art. cricoaritenóidea até o limite } \\
\text { ventral mediano }\end{array}$ \\
\hline & Cartilagem ariter \\
\hline 3а & Altura medida da base a \\
\hline $3 b$ & $\begin{array}{l}\text { Distância entre a extremidade do processo vocal e o ponto } \\
\text { central da art. cricoaritenóidea }\end{array}$ \\
\hline $3 \mathrm{c}$ & $\begin{array}{l}\text { Distância entre a extremidade do processo muscular e o ponto } \\
\text { central da art. cricoaritenóidea }\end{array}$ \\
\hline & Cartilagem epiglótica \\
\hline $4 a$ & $\begin{array}{l}\text { Comprimento desde o nível dos processos cuneiformes ao } \\
\text { ápice no plano mediano }\end{array}$ \\
\hline $4 \mathrm{~b}$ & Largura máxima \\
\hline $4 \mathrm{c}$ & Comprimento dorso-ventral no plano mediano \\
\hline $5 a$ & $\begin{array}{l}\text { Dimensões laríngeas } \\
\text { Comprimento crânio-caudal da laringe no plano mediano (do } \\
\text { ápice da cartilagem epiglote até a margem caudal da lâmina } \\
\text { cricóide) }\end{array}$ \\
\hline $5 b$ & Comprimento da parte membranosa da glote no plano mediano \\
\hline $5 c$ & $\begin{array}{l}\text { Comprimento da parte intercartilaginosa da glote no plano } \\
\text { mediano }\end{array}$ \\
\hline
\end{tabular}

$2 \mathrm{~g}, 3 \mathrm{a}, 3 \mathrm{~b}$ e $3 \mathrm{c}$ ) foram realizadas em ambos os antímeros e obtida uma média. As 23 medidas foram adaptadas dos trabalhos de Wysocki et al. (2008a), Wysocki et al. (2008b), Charuta et al. (2009) e Wysocki et al. (2010) e encontram-se listadas no Quadro 1 e esquematizadas na Figura 1. Além das dezesseis laringes mensuradas, outra laringe pertencente a um espécime fêmea foi submetida à dissecação e desarticulação das cartilagens para fotomacrografias individualizadas. Foram estabelecidas as relações de proporções das medidas 1b,1c, 1d, 1g, 2e, 3a, 3b e 3c do C. thous com mensuradas por Tayama et al. (2001) para o cão doméstico.

Em dois espécimes, um macho e uma fêmea, foram realizadas radiografias em projeção lateral da região crânio-cervical para registrar a esqueletopia da laringe. As imagens foram obtidas em aparelho da marca Phillips ${ }^{\circledR}$, modelo Aquilla Plus 300, em sistema de cassete computadorizado da marca Kodac ${ }^{\circledR}$ DirectView, empregando exposição de $50 \mathrm{Kv}, 200 \mathrm{~mA}$ e $0,1 \mathrm{~s}$.

A nomenclatura adotada para as estruturas baseou-se na Nomina Anatomica Veterinária (ICGVN, 2012).

Estudo microscópico. Após as análises macroscópicas, as dezesseis laringes foram avaliadas quanto aos aspectos histológicos. A hemilaringe direita foi submetida à clivagem sagital e a hemilaringe esquerda a seções em três níveis: dorsal (incluindo o processo corniculado da aritenoide e lâmina da cartilagem cricoide), médio (terço médio das quatro cartilagens principais) e ventral (terço ventral das quatro cartilagens principais). Posteriormente, as amostras foram embebidas em parafina e as seções histológicas com $4 \mu \mathrm{m}$ submetidas à coloração por hematoxilina e eosina. As lâminas com os cortes histológicos foram analisadas 

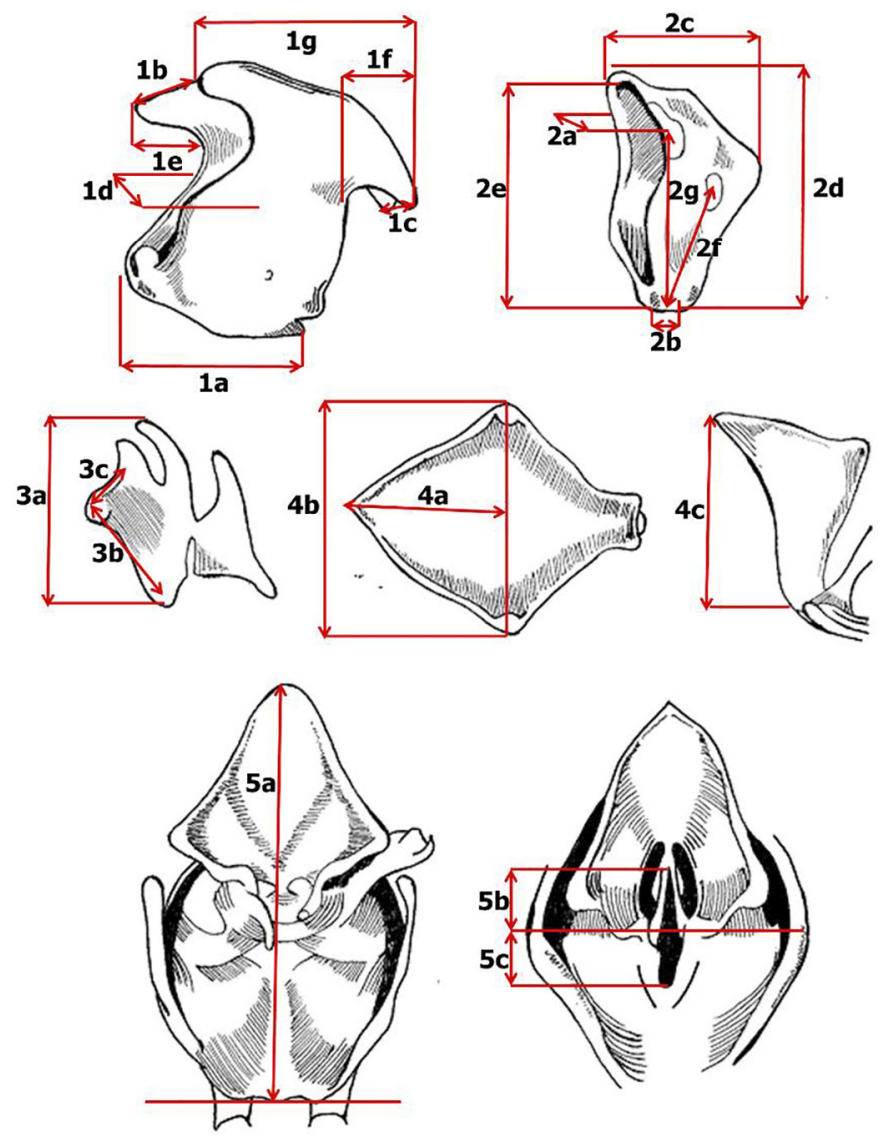

Fig.1. Representação esquemática das mensurações realizadas nas laringes de Cerdocyon thous.

em microscópico ótico de luz quanto ao tipo de cartilagem, natureza do epitélio, presença de tecido linfoide, glândulas e demais tecidos e estruturas, sendo os achados registrados em formulário. Finalmente, fotomicrografias digitais foram realizadas com câmera Olympus ${ }^{\circledR}$ DP26 associada ao software cellSens 1.7.

Análise estatística. A análise estatística consistiu de: parte descritiva (média aritmética, desvio padrão e coeficiente de variação); testes de correlação linear de Pearson entre as medidas das laringes de $C$. thous; e teste t de comparação entre as médias das medidas entre sexos (ao nível de 5\% de significância). Os dados estatísticos foram analisados com o software BioEstat $5.3^{\circledR}$.

\section{RESULTADOS}

A laringe de Cerdocyon thous dispôs-se caudalmente à raiz da língua, orofaringe e palato mole, ventralmente ao

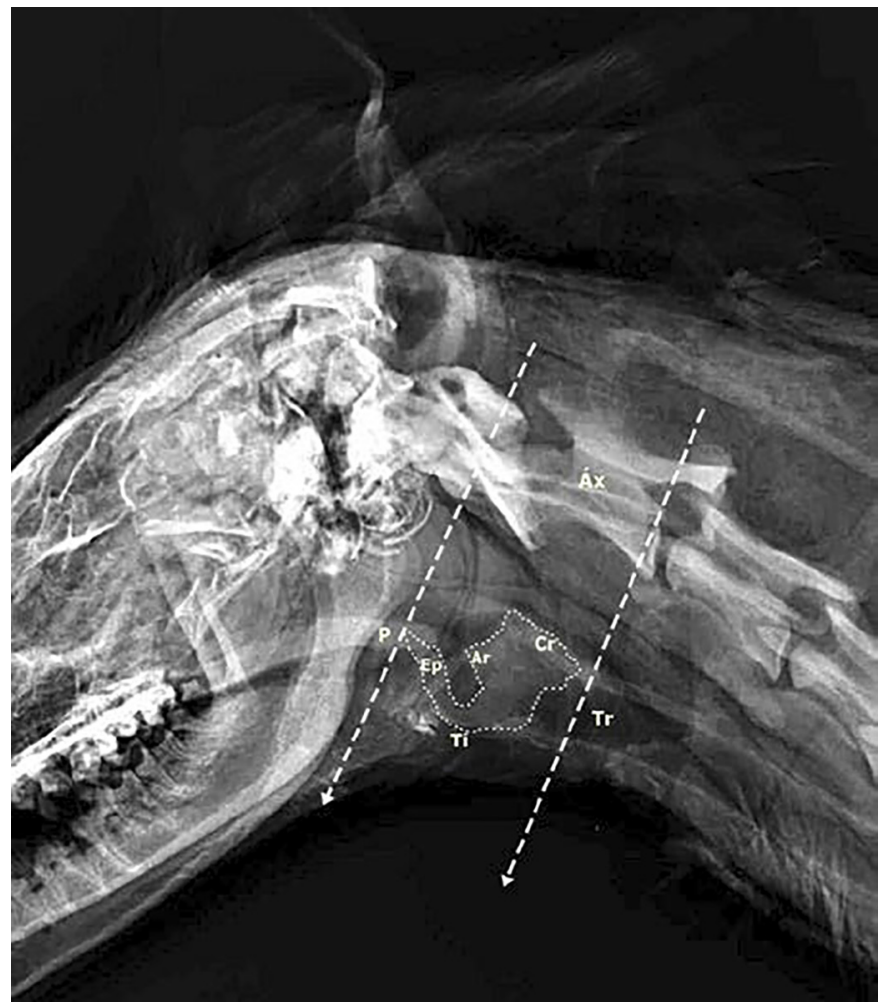

Fig.2. Imagem radiográfica em projeção lateral da região crânio-cervical de espécime fêmea, adulto, de Cerdocyon thous que evidencia a esqueletopia da laringe (contorno pontilhado). Palato mole (P). Áxis (Ax), Traqueia (Tr), Cartilagens epiglote (Ep), aritenóide (Ar), Tireoide (Ti) e Cricóide (Cr).

esôfago, dorsalmente ao m. esterno-hioideo. As radiografias permitiram evidenciar que a esqueletopia da laringe, desde a extremidade cranial (ápice da epiglote) até a caudal (lâmina cricoide), ocorreu ao nível do dente e superfície articular caudal do corpo do áxis, respectivamente (Fig.2).

Sete músculos (intrínsecos) apresentaram origem e inserção na laringe (Quadro 2). 0 aparato hioideo foi composto pelos ossos estilo-hioideo, epi-hioideo, cerato-hioideo, basi-hioideo e tireo-hioideo e mantiveram a laringe suspensa desde a bula timpânica por uma cartilagem tímpano-hioidea.

Todas as laringes de $C$. thous apresentaram uma cartilagem epiglote, uma cricoide, uma tireoide, um par de cartila-

Quadro 2. Características de origem, inserção e ação dos músculos intrínsecos da laringe encontrados em Cerdocyon thous $(\mathrm{n}=16)$

\begin{tabular}{|c|c|c|c|}
\hline Músculo & Origem & Inserção & Ação \\
\hline Cricotireoide & Face lateral da lâmina tireoide & Face lateral do arco cricóide & $\begin{array}{l}\text { Tensionar as } \\
\text { cordas vocais }\end{array}$ \\
\hline Cricoaritenóide dorsal & $\begin{array}{l}\text { Lateralmente à crista mediana da lâmina } \\
\text { cricóide }\end{array}$ & Processo muscular da aritenóide & Abrir a glote \\
\hline Cricoaritenóide lateral & Região látero-cranial da cricóide & Processo muscular da aritenóide & Fechar a glote \\
\hline Tireoaritenóide & Face interna mediana da lâmina tireoide & Face dorso-lateral da aritenóide & Fechar a glote \\
\hline Vocal & Face interna mediana da lâmina tireoide & Processo vocal da aritenóide & $\begin{array}{l}\text { Relaxar as cor- } \\
\text { das vocais }\end{array}$ \\
\hline Ventricular & Processo cuneiforme da aritenóide & Rafe mediana dorsal & $\begin{array}{l}\text { Fechar a glote e } \\
\text { dilatar o ventrí- } \\
\text { culo lateral }\end{array}$ \\
\hline Aritenóide transverso & Processo muscular da aritenóide & Rafe mediana dorsal & Fechar a glote \\
\hline
\end{tabular}




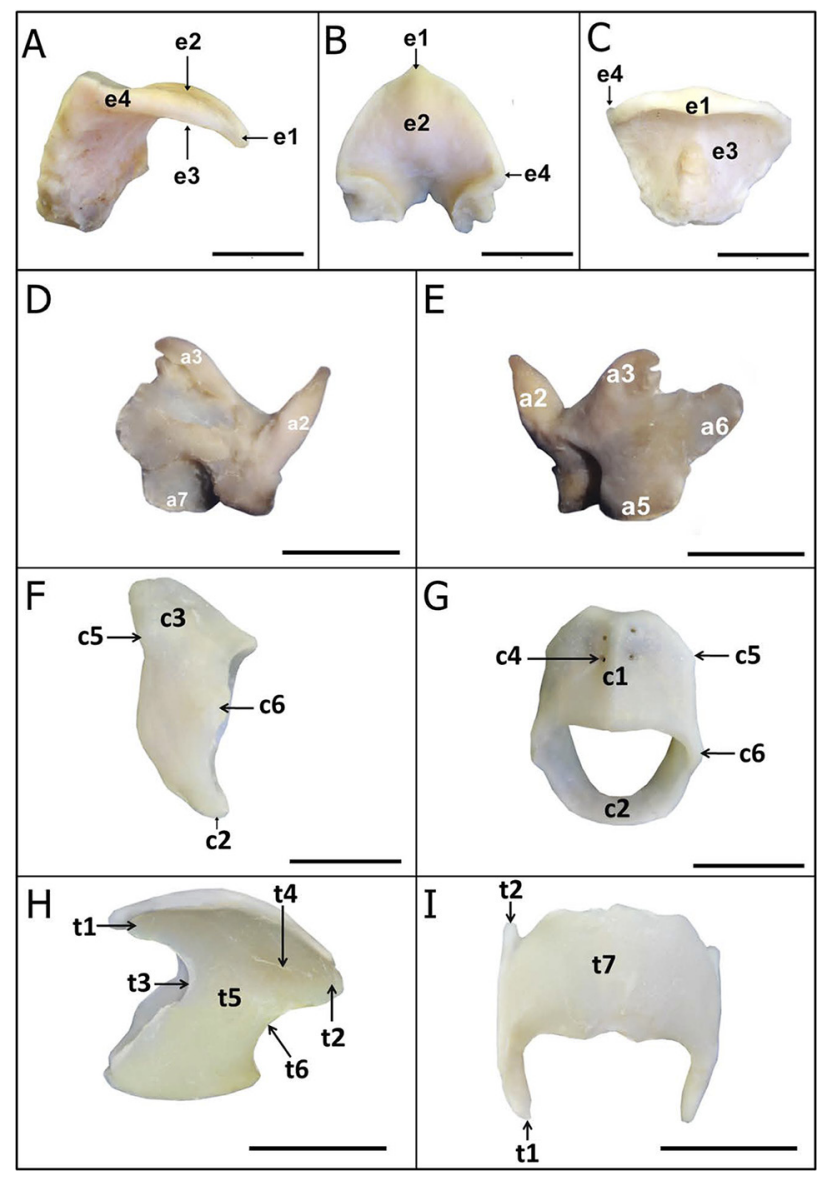

Fig.3. As cartilagens da laringe de fêmea adulta de Cerdocyon thous (A) em vistas lateral direita, (B) dorsal e (C) rostral da cartilagem epiglote; (D) vistas lateral e (E) medial da cartilagem aritenóide direita; (F) vistas lateral esquerda e (G) dorsal da cartilagem cricóide; (H) vistas lateral esquerda e ventral da cartilagem tireóide. Ápice da epiglote (e1), face laríngea (e2), face lingual (e3), prega ariepiglótica (e4), processo cuneiforme (a2), processo corniculado (a3), face medial do processo vocal (a5), face articular para a cricóide (a6), face lateral do processo vocal (a7), crista mediana (c1), arco cricóide (c2), lâmina cricóide (c3), forame vascular (c4) face articular para a aritenóide (c5) face articular para a tireoide (c6), corno rostral da tireoide ( $\mathrm{t} 1$ ), corno caudal da tireoide ( $\mathrm{t} 2$ ), fissura tireoide (t3), linha oblíqua (t4), lâmina esquerda da tireoide (t5), incisura tireóide caudal (t6), face ventral (t7). Barra $=1 \mathrm{~cm}$.

gens aritenoides (Fig.3) e outro de cartilagens sesamoides (Figs. 4 e 5). 0 comprimento total foi 29,1 $\pm 3,2 \mathrm{~mm}$ (do ápice da epiglote até a margem caudal da cricoide) e a largura máxima $20,2 \pm 2,2 \mathrm{~mm}$ (entre os cornos craniais da tireoide) (Quadro 3).

Ao nível de 5\% de significância, o teste de correlação linear revelou que o comprimento craniocaudal da lâmina da cartilagem tireoide no plano mediano (1a) foi a medida que mais frequentemente apresentou correlação com as demais (Quadro 4). As medidas 3a e 5b não apresentaram correlação significativa com nenhuma outra. A relação entre as médias das medidas obtidas no $C$. thous com as correspondentes na laringe de cães domésticos analisadas por Tayama et al. (2001) estão no Quadro 5.

A cartilagem epiglótica apresentou formato de "folha"
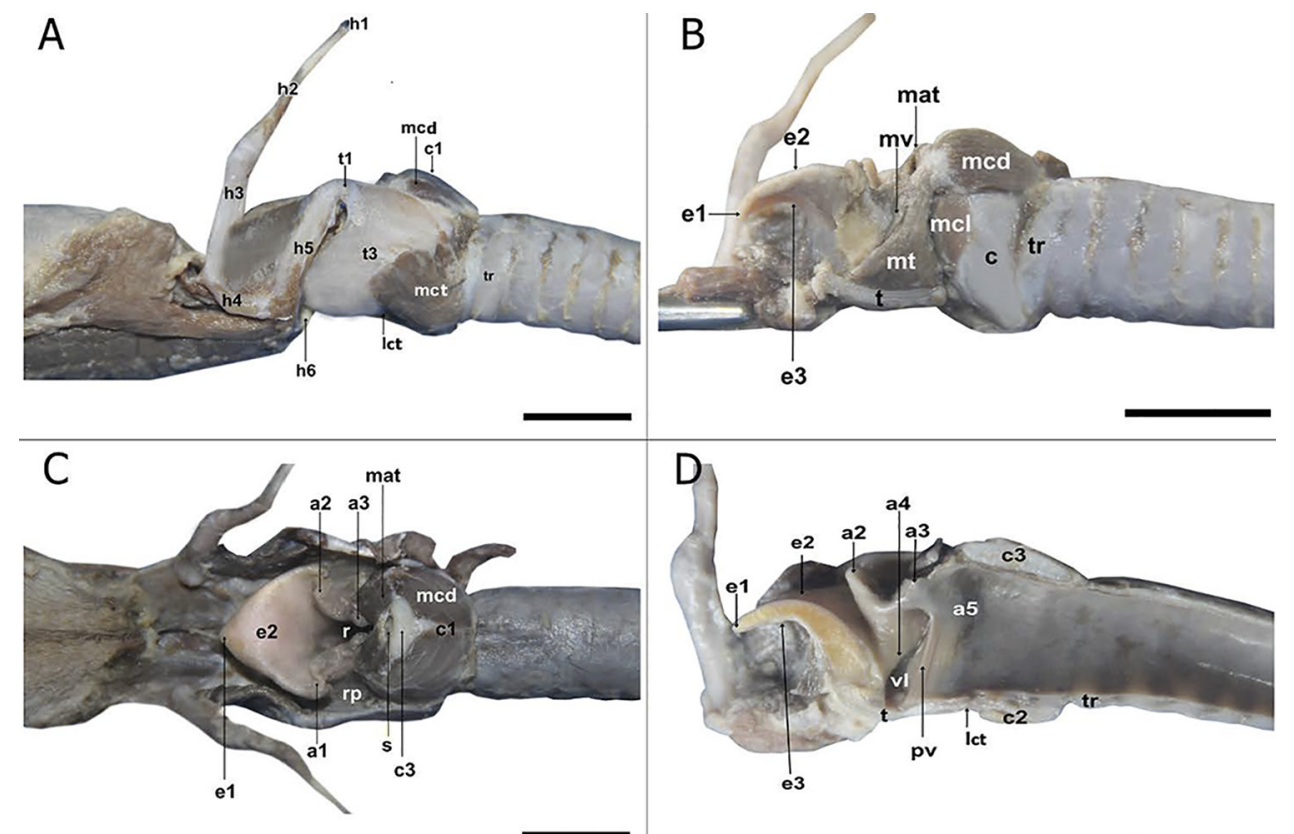

Fig.4. Laringe, aparato hioideo, raiz da língua e traqueia de espécime fêmea, adulto, de Cerdocyon thous (A) em vistas lateral esquerda após remoção dos músculos extrínsecos, (B) lateral após secção da lâmina tireoide esquerda, (C) dorsal e (D) da face medial do antímero direito. Estruturas: cartilagem tímpano-hióidea (h1), osso estilo-hióideo (h2), osso epi-hióideo (h3), osso cerato-hióideo (h4), osso tireo-hióideo (h5), osso basi-hióideo (h6), ápice da epiglote (e1), face laríngea (e2), face lingual (e3), prega ariepiglótica (a1), processo cuneiforme (a2), processo corniculado (a3), prega vestibular (a4), processo vocal (a5), cartilagem cricóide (c), crista mediana da cricóide (c1), arco da cricóide (c2), lâmina da cricóide (c3), cartilagem tireoide (t), corno rostral da tireoide (t1), lâmina esquerda da tireoide (t3), m. cricotireoideo (mct), m. cricoaritenoideo lateral (mcl), m. cricoaritenoideo dorsal (mcd), m. tireoaritenoideo (mt), m. vocal (mv), m. aritenoideo-transverso (mat), cartilagem sesamoide (s), ligamento cricotireoidiano (lct), recesso piriforme (rp), rima da glote (r), prega ventricular (pv), ventrículo lateral (vl), traqueia (tr). Barra $=1 \mathrm{~cm}$. 


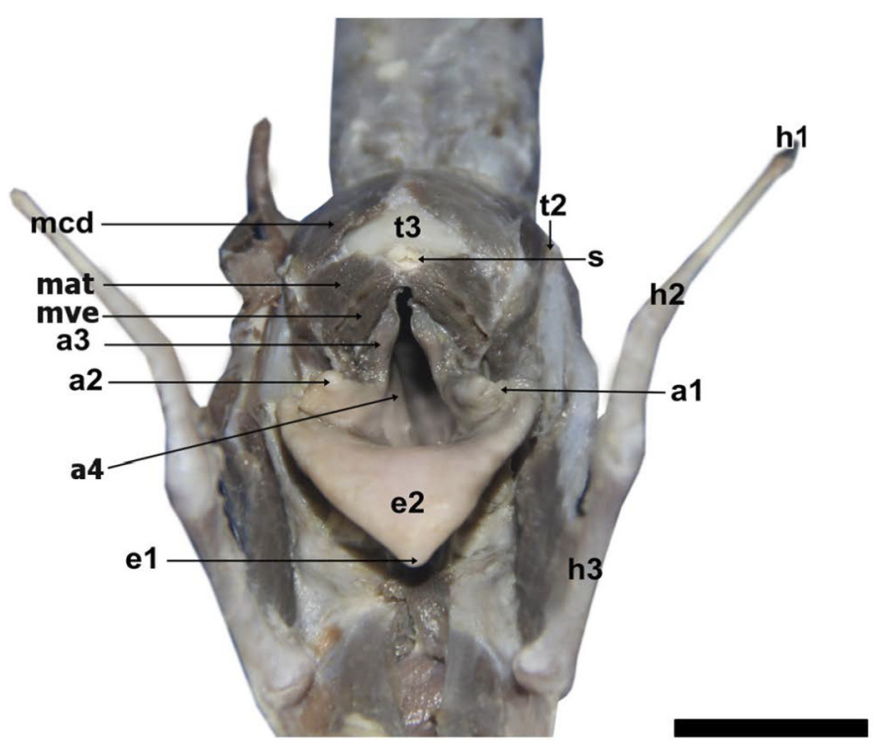

Fig.5. Laringe de espécime fêmea, adulto, de Cerdocyon thous em vista rostral. Estruturas: cartilagem tímpano-hióidea (h1), osso estilo-hióideo (h2), osso epi-hióideo (h3), ápice da epiglote (e1), face laríngea (e2), prega ariepiglótica (a1), processo cuneiforme (a2), processo corniculado (a3), prega vocal (a4), osso sesamoiode (s), corno caudal da tireoide (t2), lâmina da cricóide (t3), m. ventricular (mve), m. aritenoideo transverso (mat), m. cricoaritenoideo dorsal $(\mathrm{mcd})$. Barra $=1 \mathrm{~cm}$.

Quadro 3. Resultados das mensurações (média \pm desvio padrão), coeficiente de variação (CV) e valor de p no teste $t$ de comparação entre as médias entre sexos $(\alpha=5 \%)$ obtidos das laringes de Cerdocyon thous $(n=6)$

\begin{tabular}{cccccccc}
\hline Medida & $\begin{array}{c}\text { Geral } \\
\text { (mm) }\end{array}$ & $\begin{array}{c}\text { Machos } \\
\text { (mm) }\end{array}$ & $\begin{array}{c}\text { Fêmeas } \\
\text { (mm) }\end{array}$ & CV Geral CV Machos CV Fêmeas & p-valor \\
& $(\%)$ & $(\%)$ & \\
\hline 1a & $10,4 \pm 1,4$ & $10.1 \pm 1.6$ & $10,5 \pm 1,5$ & 13,9 & 16,3 & 13,8 & 0,65 \\
1b & $20,2 \pm 2,2$ & $21,4 \pm 2,2$ & $19,8 \pm 2,2$ & 11,1 & 10,4 & 11,1 & 0,23 \\
1c & $15,2 \pm 1,8$ & $16,3 \pm 2,7$ & $14,9 \pm 1,4$ & 11,9 & 16,8 & 9,3 & 0,20 \\
1d & $19,8 \pm 1,9$ & $20,3 \pm 2,2$ & $19,7 \pm 1,9$ & 9,7 & 10,9 & 9,6 & 0,61 \\
1e & $4,7 \pm 0,8$ & $4,8 \pm 1,2$ & $4,7 \pm 0,7$ & 17,5 & 25,1 & 15,5 & 0,85 \\
1f & $5,5 \pm 0,8$ & $5,8 \pm 0,5$ & $5,4 \pm 0,9$ & 15,1 & 8,7 & 16,9 & 0,51 \\
1g & $17,7 \pm 1,3$ & $18,1 \pm 0,9$ & $17,5 \pm 1,4$ & 7,2 & 4,7 & 7,8 & 0,43 \\
2a & $10,3 \pm 1,9$ & $10,0 \pm 1,4$ & $10,4 \pm 2,1$ & 18,3 & 14,1 & 19,8 & 0,70 \\
2b & $3,3 \pm 0,6$ & $3,4 \pm 0,8$ & $3,2 \pm 0,6$ & 18,3 & 22,2 & 17,6 & 0,64 \\
2c & $10,8 \pm 1,2$ & $11,1 \pm 1,7$ & $10,8 \pm 1,1$ & 11,1 & 14,9 & 10,1 & 0,61 \\
2d & $18,1 \pm 2,2$ & $19,3 \pm 2,4$ & $17,8 \pm 2,1$ & 12,1 & 12,5 & 11,8 & 0,26 \\
2e & $13,3 \pm 2,2$ & $14,8 \pm 4.1$ & $12,8 \pm 1,2$ & 16,9 & 27,9 & 8,9 & 0,43 \\
2f & $12,1 \pm 1,8$ & $11,5 \pm 2,3$ & $12,3 \pm 1,7$ & 14,9 & 19,8 & 13,8 & 0,49 \\
2g & $17,6 \pm 1,8$ & $17,0 \pm 3,2$ & $17,8 \pm 1,2$ & 10,1 & 18,6 & 6,7 & 0,66 \\
3a & $10,4 \pm 2,4$ & $9,9 \pm 1,3$ & $10,6 \pm 2,8$ & 23,4 & 13,3 & 25,8 & 0,64 \\
3b & $8,1 \pm 2,2$ & $10,3 \pm 2,3$ & $7,4 \pm 1,7$ & 27,2 & 22,7 & 23,0 & $0,02 *$ \\
3c & $6,8 \pm 0,9$ & $6,9 \pm 0,9$ & $6,7 \pm 0,9$ & 12,8 & 12,4 & 13,4 & 0,78 \\
4a & $9,9 \pm 1,4$ & $10,3 \pm 1,5$ & $9,8 \pm 1,4$ & 14,4 & 14,9 & 14,6 & 0,53 \\
4b & $13,5 \pm 1,9$ & $12,4 \pm 1,8$ & $13,8 \pm 1,9$ & 14,1 & 14,5 & 13,5 & 0,19 \\
4c & $14,4 \pm 1,8$ & $14,6 \pm 1,9$ & $14,3 \pm 1,9$ & 12,8 & 12,9 & 13,3 & 0,78 \\
5a & $29,1 \pm 3,2$ & $30,3 \pm 3,3$ & $28,7 \pm 3,2$ & 10,8 & 10,8 & 11,0 & 0,41 \\
5b & $8,9 \pm 1,1$ & $9,5 \pm 0,6$ & $8,7 \pm 1,2$ & 12,5 & 6,1 & 13,7 & 0,23 \\
5c & $8,0 \pm 1,4$ & $7,7 \pm 0,7$ & $8,1 \pm 1,6$ & 17,9 & 9,1 & 19,9 & 0,46
\end{tabular}

* Diferença significativa ao nível de $5 \%$.

com o ápice voltado cranialmente e relacionado dorsalmente com a extremidade caudal do palato mole. Formou um discreto pecíolo voltado caudoventralmente e faces laríngea côncava e lingual convexa (Fig.6). À análise histológica mostrou-se invariavelmente elástica, com diferentes

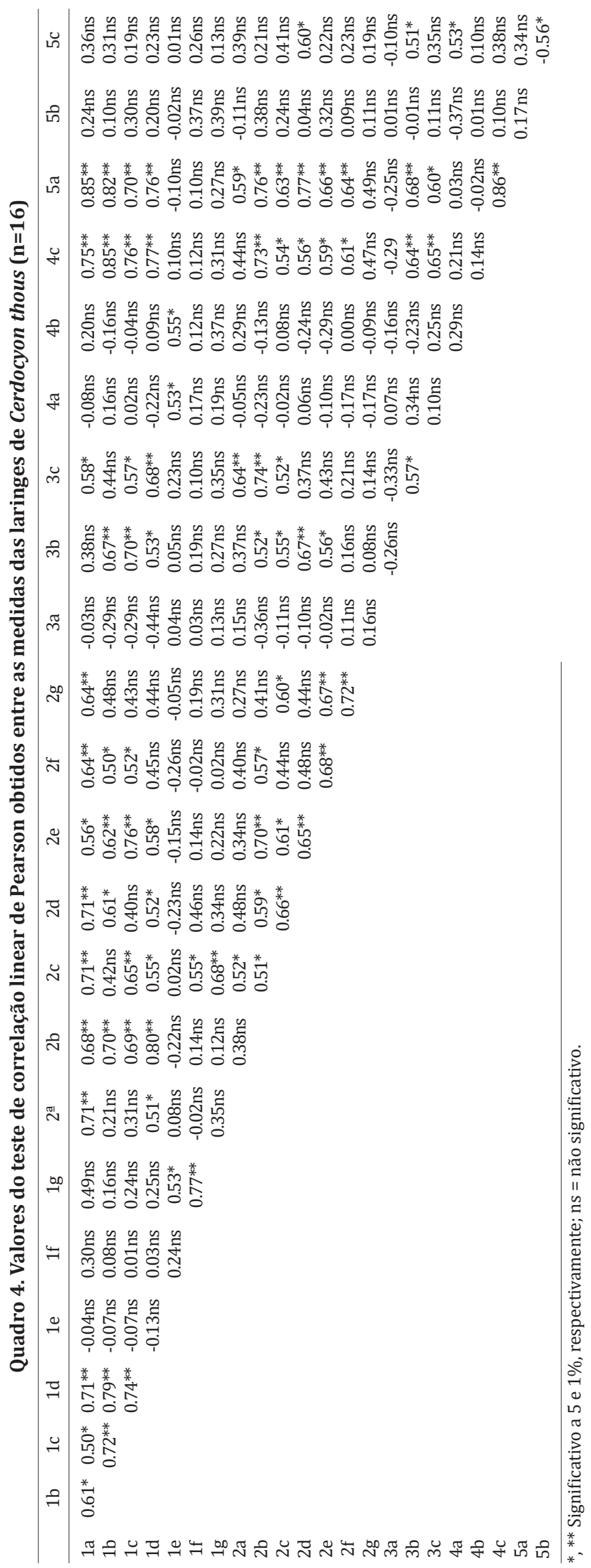


Quadro 5. Relação entre as médias das mensurações (mm) da laringe do cão doméstico* e de Cerdocyon thous

\begin{tabular}{cccc}
\hline Medidas & C.thous $(\mathrm{n}=16)$ & Cão $(\mathrm{n}=9)^{*}$ & Relação \\
\hline 1b & 20,2 & 40,1 & 0,50 \\
1c & 15,2 & 27,5 & 0,55 \\
$1 \mathrm{~d}$ & 19,8 & 34,8 & 0,56 \\
$1 \mathrm{~g}$ & 17,7 & 32,5 & 0,54 \\
$2 \mathrm{e}$ & 13,3 & 29,4 & 0,45 \\
3a & 10,4 & 14,5 & 0,71 \\
3b & 8,1 & 10,3 & 0,78 \\
3c & 6,8 & 5,5 & 1,23
\end{tabular}

* Segundo Tayama et al. (2001).

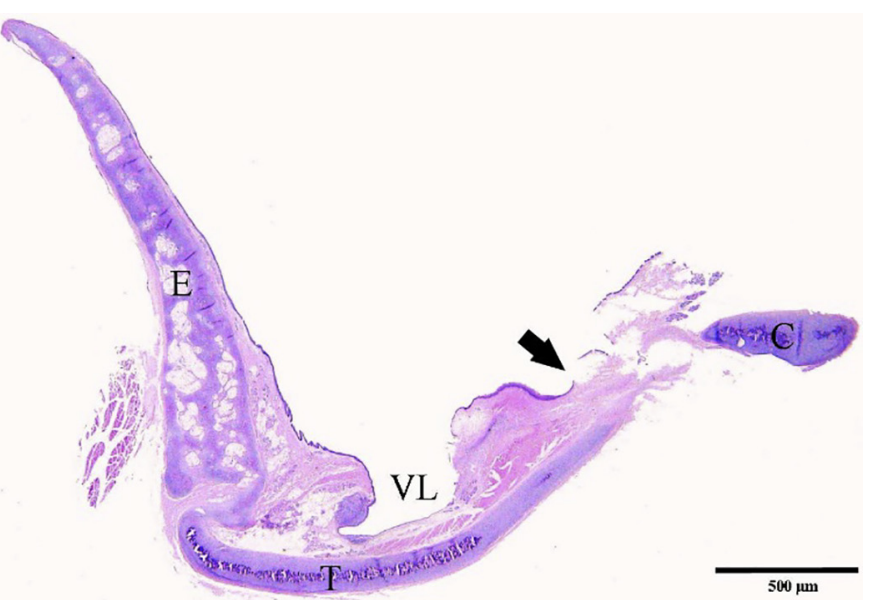

Fig.6. Corte sagital de laringe de espécime fêmea de Cerdocyon thous. São observadas as cartilagens epiglote (E), tireoide (T) e cricóide (C). Paralelo ao terço médio da cartilagem tireoide é possível observar o aprofundamento do epitélio e formação do ventrículo lateral da laringe (VL). Notar a área de transição entre o epitélio pavimentoso estratificado para epitélio pseudoestratificado cilíndrico ciliado próximo ao terço final da cartilagem tireoide (seta). Hematoxilina e eosina. Barra $=500 \mu \mathrm{m}$.

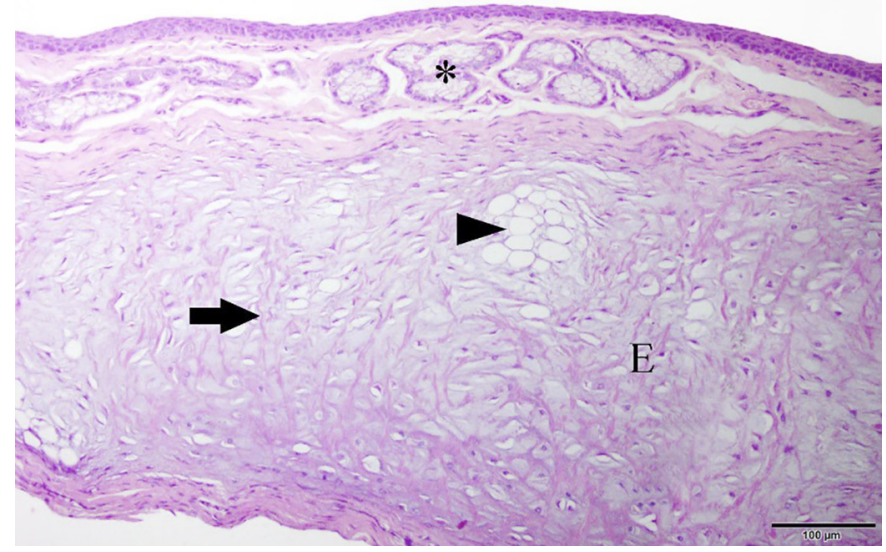

Fig.7. Corte sagital de laringe de um espécime fêmea de Cerdocyon thous. Cartilagem epiglote (E) revestida dorsalmente por epitélio estratificado pavimentoso. Observam-se condrócitos entremeados por fibras elásticas eosinofílicas (seta) e com ilhas de adipócitos que podiam ser observadas em graus variados em toda a extensão da epiglote (cabeça de seta). Notam-se ainda estruturas glandulares mistas tubuloacinares na face dorsal da lâmina própria da epiglote (*). Hematoxilina e eosina. Barra $=100 \mu \mathrm{m}$. graus de áreas com tecido adiposo e de glândulas mistas tubuloacinares na lâmina própria (Fig.7). Em duas laringes foi possível visualizar também corpúsculos gustativos junto ao epitélio da face laríngea ao nível do terço caudal da epiglote. Uma comunicação entre a base da cartilagem epiglote e a parte mediana rostral da lâmina tireoidea evidenciou a transição entre os tipos cartilaginosos elástico e hialino (Fig.8).

As cartilagens aritenoides apresentaram-se pares, com forma irregular e compreenderam os processos cuneiforme, corniculado, vocal e muscular (Fig.3). A face articular para a cartilagem cricoide mostrou-se côncava e ovalada e

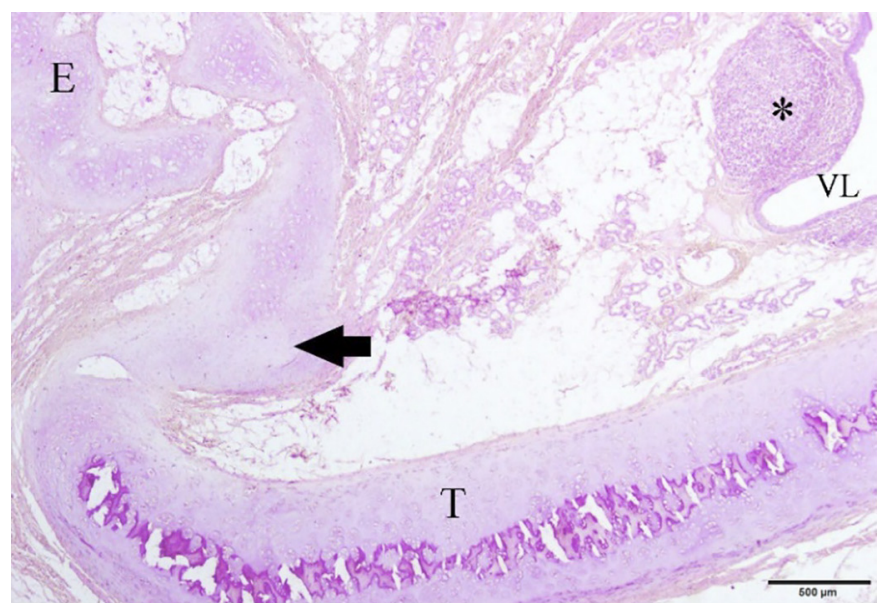

Fig.8. Corte sagital de laringe de um espécime fêmea de Cerdocyon thous. Observa-se a região de transição (seta) entre as cartilagens epiglote (E) e tireoide (T). No canto superior direito percebe-se a região mais profunda do ventrículo lateral (VL) com agregado linfoide associado a mucosa $\left({ }^{*}\right)$. Hematoxilina e eosina. Barra $=500 \mu \mathrm{m}$.

prolongou-se láteroventralmente para formar o processo muscular. O curto processo corniculado limitou dorsalmente a entrada da laringe. 0 processo vocal dispôs-se ventrocaudalmente. 0 processo cuneiforme formou a parte mais cranial da cartilagem e dividiu-se em duas partes: uma dorsal, maior, que formou a prega ariepiglótica e uma ventral, discreta, da qual partiu a prega vestibular. Lateralmente à prega ariepiglótica formou-se um recesso piriforme. A cartilagem aritenoide exibiu composição mista, mostrando-se elástica nos processos cuneiforme e corniculado e hialina nos processos vocal e muscular (Fig. 9). As cartilagens sesamoides, pares e inconspícuas, posicionaram-se entre o processo corniculado da aritenoide e a margem rostral da lâmina cricoide.

A cartilagem tireoide foi a maior da laringe. Consistiu de duas lâminas, uma em cada antímero, unidas ventralmente no plano mediano e afastadas dorsalmente (Fig.3). Exibiu uma discreta linha oblíqua na face lateral para a inserção do m. esterno-tireoideo. Cada lâmina expandiu-se rostral e caudalmente para formar os respectivos cornos: o rostral articulou-se com o osso tireo-hioideo; o caudal com a cartilagem cricoide. Entre o corno rostral e a lâmina visualizou-se uma fissura tireoide. Uma discreta incisura tireoide caudal também pode ser reconhecida. Apresentou natureza hialina, com diferentes graus de diferenciação em matriz 


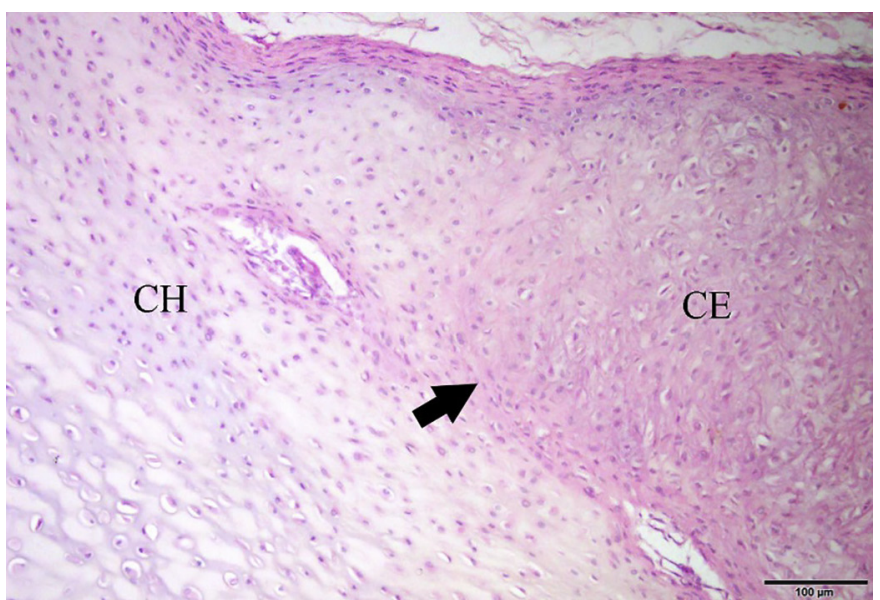

Fig.9. Corte sagital de laringe de um espécime fêmea de Cerdocyon thous. Nota-se a zona de transição (seta) entre as cartilagens hialina $(\mathrm{CH})$ e a elástica (CE) na cartilagem aritenóide. Hematoxilina e eosina. Barra $=100 \mu \mathrm{m}$.

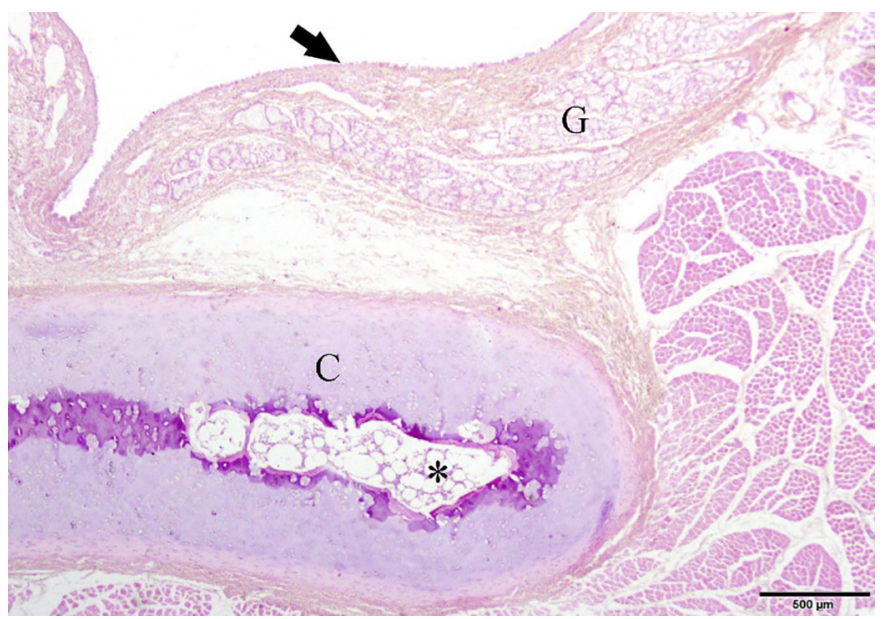

Fig.10. Corte sagital de laringe de um espécime fêmea de Cerdocyon thous. Cartilagem cricóide (C) com área central contendo trabéculas de matriz osteoide medula óssea $\left(^{*}\right)$. Nessa região a laringe apresenta-se revestida internamente por epitélio pseudoestratificado cilíndrico ciliado (seta). Nota-se ainda grande quantidade de glândulas mistas tubuloacinares na lâmina própria (G). Hematoxilina e eosina. Barra $=500 \mu \mathrm{m}$.

osteoide e formação de trabéculas ósseas e medula óssea no interior.

A cartilagem cricoide formou um anel completo (Fig.3). A lâmina dorsal, cerca de três vezes mais ampla que o arco ventral, exibiu uma crista mediana bem desenvolvida e acompanhada por um par de forames vasculares em cada lado da sua extremidade rostral. 0 arco apresentou uma inclinação caudal da sua parte mais ventral. A borda rostral da lâmina apresentou uma face articular para a cartilagem aritenoide e a borda caudal uma face para a cartilagem cricoide. As duas junções tinham natureza sinovial. Assim como cartilagem tireoide, mostrou-se hialina com matriz osteóide, trabéculas ósseas e medula óssea (Fig.10). No entanto, o epitélio da cartilagem cricoide foi pseudoestratificado cilíndrico ciliado, enquanto o epitélio predominante em todo o restante da laringe foi do tipo pavimentoso estratificado.

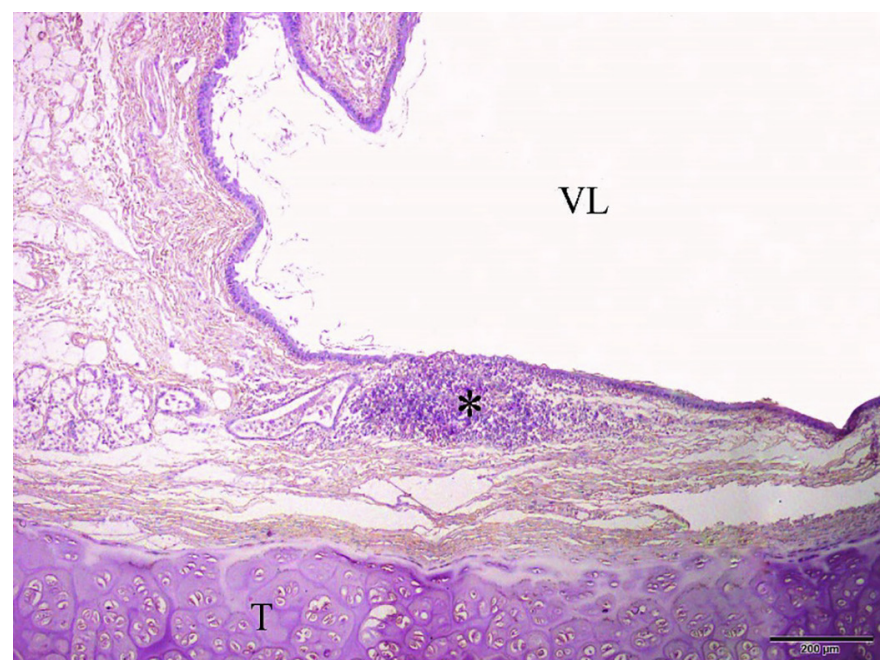

Fig.11. Laringe de um espécime fêmea de Cerdocyon thous. Corte sagital da laringe na região do ventrículo lateral (VL) que apresenta agregado linfóide associado à mucosa $\left(^{*}\right)$. Pode-se perceber o tipo hialino da cartilagem tireoide, caracterizada por condrócitos basofílicos. Hematoxilina e eosina. Barra = $200 \mu \mathrm{m}$.

Ao corte mediano puderam ser observadas as pregas vestibular e vocal, entre as quais formou-se um amplo ventrículo lateral (Fig.4). 0 ventrículo exibiu formação de tecido linfoide associado à mucosa em região de epitélio estratificado (Fig. 11).

\section{DISCUSSÃO}

A laringe de Cerdocyon thous apresentou eixo longitudinal em continuidade horizontal com o corpo da mandíbula, o que é típico de mamíferos quadrúpedes (Saigusa 2011). De fato, a morfologia laríngea é marcadamente constante na classe Mammalia mesmo com as diferenças consideráveis entre porte corporal, padrão de fonação e estilo de vida das espécies (Harrison 1995). Entre aquelas com descrição na literatura, a laringe de $C$. thous exibiu maior semelhança com a do cão doméstico. Isto se acentua quando comparados a conformação das cartilagens, ossos do aparato hioideo e músculos intrínsecos. Entretanto, ocupou posição predominantemente ventral ao áxis e não ao atlas (Adaro et al. 2004, Evans \& Lahunta 2013). Em Didelphis sp. situa-se ventralmente ao atlas e áxis (Bertassoli et al. 2013) enquanto na Dasyprocta sp. posiciona-se na região cervical caudal devido ao maior comprimento da língua (Silva et al. 2014). Enquadrou-se, portanto, na generalização de que a esqueletopia da laringe dos mamíferos terrestres se estende desde a base do occipital ou primeiras vértebras cervicais até o nível da terceira ou quarta vértebras cervicais (Harrison 1995).

$O$ aparato hioideo de $C$. thous evidenciou uma parte suspensória formada pelos ossos cerato-hioideo, epi-hioideo e estilo-hioideo. 0 osso tireo-hioideo articulou-se dorsalmente com o corno rostral da cartilagem tireoide e ventralmente com o osso basi-hioideo. Esta configuração é idêntica à descrita para o cão doméstico por Evans \& Lahunta (2013) e para os carnívoros silvestres Vulpes vulpes, Nyctereutes procyonoides, Ursus thibetanus, Procyon lotor, Martes 
melampus, Mustela itatsi, Mustela sibirica e Paguma larvata por Takada et al. (2009).

Ao consultar descrições da anatomia laríngea de cães domésticos em livros-texto, constataram-se algumas diferenças: a epiglote de $C$. thous mostrou-se mais curta no eixo dorso-ventral, apresentou contorno lateral mais arrendondado e o pecíolo quase inaparente; a epiglote formou cerca de um terço do comprimento total da laringe, enquanto em cães corresponde à metade (Evans \& Lahunta 2013); a cartilagem tireoide de $C$. thous apresentou fissura tireoidiana mais profunda, porém proeminência laríngea ventral, incisura tireoidea caudal e linha oblíqua inconspícuas; a cricoide revelou uma lâmina apenas três vezes mais ampla do que o arco ventral, enquanto no cão é cinco vezes, e o par de forames vasculares foi constante e não ocasional como nos cães (Evans \& Lahunta 2013); a crista mediana da cricoide apareceu mais elevada e não foi visualizada a rasa incisura mediana na margem rostral da lâmina cricoide descrita para o cão (Hare 1986). As aritenoides de $C$. thous apresentaram os mesmos processos que as do cão doméstico, porém a parte ventral do processo cuneiforme exibiu-se mais curta e o processo corniculado menos desenvolvido.

Tayama et al. (2001) e Kim et al. (2004) propuseram um esquema de mensurações laríngeas com ênfase na identificação de espécies que pudessem servir como modelos experimentais à laringe humana. No presente trabalho optou-se por seguir o protocolo de medidas de Wysocki et al. (2008b), embora a adoção de todos os pontos mensurados por Tayama et al. (2001) à laringes de cães pudesse ser mais conveniente para fins comparativos. Esta escolha embasou-se no fato de o grupo de Wysocki (2008a, 2008b e 2010) ter publicado mais recentemente uma série de artigos com mensurações de laringes animais e humanas, o que facilita uma comparação mais abrangente. Além disto, os trabalhos de Tayama et al. (2001) e de Kim et al. (2004) não propuseram mensurações da epiglote.

Não obstante, oito distâncias mensuradas em laringes de cães por Tayama et al. (2001) puderam ser comparadas com as de $C$. thous. As medidas das cartilagens tireoide e cricoide de $C$. thous foram praticamente a metade das obtidas em nove cães domésticos mestiços (massa corporal média de 23kg); apenas a aritenoide não acompanhou tais proporções. Isto embasa a constatação de que a aritenoide é a cartilagem com maior variação morfológica entre os mamíferos (Evans \& Lahunta 2013).

Embora o comprimento craniocaudal da lâmina da cartilagem tireoide no plano mediano (1a) tenha sido a medida que mais se correlacionou com as demais, outras que também apresentaram elevada frequência de forte correlação com as demais foram 1b, 1c, 1d, 2b, 2c, 2d e 2e, 4c e 5a. A correlação significativa entre muitas das medidas revela que a laringe é um órgão estruturado proporcionalmente, conforme constatado com metodologia similar em laringes de equinos por Charuta et al. (2009).

Ainda que pouco estudadas em mamíferos, características de dimorfismo sexual na laringe são reconhecidas em seres humanos (Maue \& Dickson 1971, Wysocki et al. 2008a), bovinos (Wysocki et al. 2008b) e renas (Frey et al. 2007), embora não encontradas em cães domésticos (Tayama et al. 2001), equinos (Charuta et al. 2009) nem suínos (Wysocki et al. 2010). De acordo com Harrison (1995) na maioria das espécies a laringe dos machos seria maior que a das fêmeas e isto decorreria de um porte corporal maior, mas também de uma alta afinidade de receptores de andrógenos nas cartilagens laríngeas. Tuohimaa et al. 1981 confirmaram essa hipótese em carneiros e concluíram que a cartilagem tireoidea foi a que mais sofreu influência dos hormônios masculinos.

Quando comparadas as 23 medidas laríngeas entre machos e fêmeas de $C$. thous, apenas uma demonstrou diferença significativa: a distância entre a extremidade do processo vocal ao centro da cápsula cricoide. 0 processo vocal da aritenoide é o ponto de inserção do músculo vocal e sua conformação mais alongada nos machos pode relacionar-se com diferenças na vocalização entre os sexos. Uma vez que esta medida apresentou coeficiente de variação elevado (cerca de $25 \%$ ), a atribuição de dimorfismo sexual à laringe do $C$. thous baseada apenas nessa medida parece não se sustentar. Coincidentemente, esta medida também diferiu entre suínos machos e fêmeas com idade entre 12 a 18 semanas, porém não se repetiu em suínos adultos (Wysocki et al. 2010).

A natureza elástica da cartilagem epiglote e dos processos cuneiforme e corniculado da aritenoide configura um sistema flexível, comparado a "molas" por Fink \& Demarest (1978), que atua de forma dinâmica para evitar a broncoaspiração de líquidos ou sólidos. Contrariamente, as cartilagens cricoide, tireoide e a parte caudal da aritenoide são constituídas por cartilagem hialina, o que garante uma rigidez necessária para fixação de músculos que promovem movimentos entre as mesmas. Há uma premissa de que mobilidade articular entre as cartilagens tireoide e cricoide seja o fator mais importante na produção e modulação do som nos mamíferos (Harrison 1995). Do ponto de vista mecânico, as cartilagens hialina e elástica diferem entre si pois resistem a forças de compressão e tensão, respectivamente (Harrison 1995).

0 epitélio escamoso estratificado delineou a maior parte da laringe e fez transição com o epitélio pseudoestratificado colunar ciliado (respiratório) antes de chegar à traqueia, conforme descrito para mamíferos domésticos (Bacha JR. \& Bacha 2000, Eurell 2004, König \& Liebich 2011). Em Nasua nasua, mesmo a cartilagem cricoide foi descrita como revestida por epitélio estratificado (Oliveira et al. 2011).

A presença de tecido linfoide nodular entre o epitélio e as cartilagens da laringe é conhecida em mamíferos domésticos (Banks 1991, Eurell 2004). No entanto, a localização específica dentro do ventrículo lateral da laringe somente foi aludida por Delahunty \& Cherry (2007) para seres humanos. Contudo, é provável que esta ocorrência apareça também em outros mamíferos. De todo modo, estudos em suínos comprovaram que a laringe contém importantes estruturas linfoides que exercem vigilância imunológica e reconhecimento de antígenos locais (Barker et al. 2006).

0 ápice da epiglote em $C$. thous se relacionou com a face dorsal da extremidade caudal do palato mole, o que 
configurou um posicionamento mais intranarial do que intraoral, à semelhança do descrito para o cão doméstico (Evans \& Lahunta 2013) e Mustela putorius furo (Larson 1993). A posição intranarial seria favorável para permitir que o animal respire e ingira líquido simultaneamente. Todos os mamíferos possuem cartilagem epiglote, ainda que suas dimensões, formato e presença de glândulas não estejam bem relacionados com o estilo de vida de cada espécie (Harrison 1995). Observou-se que a epiglote de $C$. thous foi ampla o suficiente para ocluir toda a glote e, assim, privilegiar o fluxo do ar para as vias olfatórias. Esta característica é especialmente relevante para carnívoros (Harrison 1995). Reforçando essa observação, Adaro et al. (2004) mencionam que a epiglote dos cães é proporcionalmente maior que a dos seres humanos.

A observação de que a cartilagem epiglote de $C$. thous é elástica e parcial ou totalmente infiltrada por tecido adiposo, com epitélio do tipo escamoso estratificado não-queratinizado, coincide com a descrição de Bacha \& Bacha (2000) para carnívoros domésticos. Segundo Bertassoli et al. (2013) há epitélio pseudoestratificado respiratório na região caudal da epiglote em Didelphis sp., o que não foi visto em $C$. thous. A presença de glândulas mistas tubuloacinares na lâmina própria da epiglote de $C$. thous também foi relatada em animais domésticos por Banks (1991) e Bacha \& Bacha (2000) e em Nasua nasua por Oliveira et al. (2011). Uma área de transição das cartilagens elástica e hialina foi visualizada na junção entre a epiglote e a tireoide. Em animais domésticos, tal união ocorre por fibras elásticas (König \& Liebich 2011). A presença de corpúsculos gustativos, visualizados na epiglote de dois espécimes de $C$. thous, coincidiu com o relatado para carnívoros, suínos, ruminantes e seres humanos por Banks (1991).

A cartilagem aritenoide revelou composição mista, sendo elástica nos processos cuneiforme e corniculado e hialina no restante. Isto coincide com o descrito genericamente para mamíferos domésticos por Dyce et al. (2010) em que ambos os processos formam-se de cartilagem do tipo elástica. Difere de Nasua nasua em que é descrita apenas como hialina (Oliveira et al. 2011), e de Didelphis sp. em que apenas o processo corniculado tem constituição elástica (Bertassoli et al. 2013).

Os processos corniculados têm a função de evitar que alimentos volumosos e ricos em líquido sejam broncoaspirados. Por esta razão, Harrison (1995) postula que tais processos são alongados nos herbívoros, especialmente nos ruminantes. Em carnívoros obrigatórios, como os felinos domésticos e o Panthera tigris, estes processos sequer são identificados (Hare 1986, Pérez et al. 2006). Deste modo, os processos corniculados curtos das aritenoides de C. thous seriam compatíveis com a dieta onívora da espécie (Kasper et al. 2014). 0 mesmo foi verificado no também onívoro Nasua nasua (Oliveira et al. 2011). De fato, estudos comparativos entre mamíferos sugerem que a morfologia laríngea relaciona-se mais com a dieta do que a características como vocalização ou velocidade de locomoção (Harrison 1995). Em C. thous, assim como no cão doméstico (Evans \& Lahunta 2013), os processos corniculados e cuneiformes pertenceram à cartilagem aritenoide; nos se- res humanos tratam-se de cartilagens distintas (Adaro et al. 2004).

A cartilagem tireoide foi a maior e formou uma ampla lâmina que garante uma proteção ventrolateral para a manutenção da natureza tubular do órgão. Isto é uma característica que se repete em mamíferos domésticos (König \& Liebich 2011) e em Nasua nasua (Oliveira et al. 2011). Em Dasyprocta sp. a cricoide foi a mais ampla das cartilagens (Silva et al. 2014). Aliado a isto, a articulação do tipo sinovial entre as cartilagens tireoide e cricoide revela que a laringe de $C$. thous é uma estrutura típica de espécies mamíferas mais recentes (Harrison 1995).

A cartilagem cricoide apresentou uma crista mediana bem desenvolvida para a fixação de músculos, bem como dimensões de altura e largura visualmente comparáveis às do primeiro anel traqueal, assim como descrito para Nasua nasua e Dasyprocta sp. (Oliveira et al. 2011, Silva et al. 2014). Tais características também são comuns nos mamíferos (Harrison 1995). A articulação cricoaritenoide, sinovial, exibiu configuração que permite o deslizamento da aritenoide sobre a cricoide possibilitando a adução e abdução da prega vocal para modular a fonação (Adaro et al. 2004). Em Didelphis sp. a cartilagem cricoide tem o formato de letra "V" (Bertassoli et al. 2013).

A semelhança entre a disposição anatômica do ligamento cricotireoidiano do $C$. thous com o cão doméstico permite supor que a cricotireoidostomia possa ser empregada como procedimento veterinário de emergência em zoológicos e unidades de conservação. Tal intervenção permite o fluxo de ar em animais com grave obstrução das vias superiores (por trauma facial, por exemplo) com uma série de vantagens sobre a traqueostomia (Fludge 2009).

Em cortes histológicos da maioria dos espécimes de $C$. thous foi visualizada ossificação com presença, inclusive, de medula óssea nas cartilagens tireoide e/ou cricoide. Um processo degenerativo que leve à calcificação seguida de ossificação em partes das cartilagens hialinas da laringe é relatado como relacionado ao envelhecimento em seres humanos (Hately et al. 1965) e animais domésticos, especialmente no equino (König \& Liebich 2011). Também foi encontrada na cartilagem cricoide de indivíduos machos de Dasyprocta sp., ainda que a idade não fosse relatada na metodologia (Silva et al. 2014).

A presença de medula óssea na laringe pode ser vista em estágios iniciais de ossificação e, ocasionalmente, na ausência de formação óssea (Harrison 1995). Todos os cadáveres usados neste estudo tinham a dentição permanente, portanto adultos. Evidências sugerem que a maioria dos espécimes de $C$. thous atropelados em rodovias sejam adultos jovens, não sendo comuns indivíduos filhotes nem senis (Silva et al. 2010), o que parece compatível com a amostragem analisada no presente estudo. Assim, talvez os sinais de calcificação/ossificação da laringe de $C$. thous surjam em idade mais precoce que a referida para animais domésticos.

A presença e a conformação das cartilagens sesamoides foram investigadas desde longa data em carnívoros silvestres. Em C. thous surgiram unidas por um tecido fibroso (ligamento), conforme aludido por Brandt (1826) para Canis 
lupus, Thalarctos maritimus e Gulo gulo, por Morel (1951) para Meles meles, por Morel \& Thiéry (1953) para Lutra lutra e por Pierard (1965) para Vulpes fulva, Urocyon cinereoargentus, Ursus americanos, Mustela vison e ocasionalmente para Canis familiaris.

Por fim, pode-se inferir que a laringe de $C$. thous constituiu-se de cartilagens, músculos, aparato hioideo e revestimento epitelial com natureza, disposição e proporções semelhantes à do cão doméstico. Diferiu quanto ao formato e dimensões das cartilagens aritenoides e na topografia ventral ao áxis.

\section{REFERÊNCIAS}

Adaro L., Rico B., Flores E. \& Cattaneo G. 2004. Laringe canina y humana: un estudio para establecer homología. Arq. Ciênc. Vet. Zool. Unipar 7:135-139.

Bacha Jr W.J. \& Bacha L.M. 2000. Color Atlas of Veterinary Histology. 2nd ed. Lippincott Williams and Wilkins, Philadelphia. 318p.

Banks W.J. 1991. Histologia Veterinária Aplicada. 5aa ed. Manole, São Paulo. $502 p$.

Barker E., Haverson K., Stokes C., Birchall M. \& Bailey M. 2006. The larynx as an immunological organ: immunological architecture in the pig as a large animal model. Clin. Exp. Immunol. 143:6-14.

Bertassoli B., Santos A., Oliveira F., Oliveira D., Assis-Neto A. \& Carvalho A. 2013. Morfologia da laringe e traquéia de Gambás (Didelphis sp.). Ciênc. Anim. Bras. 14:222-229.

Brandt J. 1826. Observationes anatomicae de instrumento Vocis mammalium. F.A. Herbig., Wien. 38p.

Charuta A., Dzierzecka M. \& Wysocki J. 2009. Evaluation of sexual dimorphism in horses on the basis of the morphology and morphometry of the larynx. Bull. Vet. Inst. Pulawy. 53:477-486.

Cheida C.C., Nakano-Oliveira E., Fusco-Costa R., Rocha-Mendes F. \& Quadros J. 2006. Ordem Carnivora, p.231-276. In: Reis N.R., Perachi A.L., Pedro W.A. \& Lima I.P. (Eds), Mamíferos do Brasil. Nelio R. dos Reis, Londrina.

Delahunty J.E. \& Cherry J. 2007. The laryngeal saccule. J. Laryngol. Otol. 83:803-815.

Dyce K., Sack W. \& Wensing C. 2010. Tratado de Anatomia Veterinária. 4a ed. Elsevier, Rio de Janeiro. 856p.

Eckel H., Sittel C., Zorowka P. \& Jerke A. 1994. Dimensions of the laryngeal framework in adults. Surg. Radiol. Anat. 16:31-36.

Erdoğan S. \& Pérez W. 2013. Anatomical characteristics of the larynx in giraffe (Giraffa camelopardalis). J. Morphol. 30:266-271.

Eurell J.A.C. 2004. Veterinary Histology. Teton NewMedia, Salt Lake City. 120 p.

Evans H.E. \& Lahunta A. 2013. Miller's Anatomy of the Dog. Saunders Elsevier, St Louis. 872p.

Fink B. \& Demarest R. 1978. Laryngeal Biomechanics. Harvard University Press, Cambridge. 176p.

Fludge M. 2009. Endotracheal intubation, p.72-74. In: Silverstein D. \& Hopper K. (Eds), Small Animal Critical Care Medicine. Saunders Elsevier, Missouri.

Frey R., Gebler A. \& Fritsch G. 2007. Nordic rattle: the hoarse vocalization and the inflatable laryngeal air sac of reindeer (Rangifer tarandus). J. Anat. 210:131-159.

Hare H. 1986. Sistema respiratório do carnívoro, p.1465-1480. In: Getty R. (Ed.), Anatomia dos Animais Domésticos. 5aa ed. Guanabara Koogan, Rio de Janeiro. 2000p.

Harrison D.F.N. 1995. The Anatomy and Physiology of the Mammalian Larynx. Cambridge University Press, Cambridge. 288p.
Hately W., Evison G. \& Samuel E. 1965. The pattern of ossification in the laryngeal cartilages: a radiological study. Brit. J. Radiol. 38:585-591.

Hirano M., Kurita S., Yukizane K. \& Hibi S. 1989. Asymmetry of the laryngeal framework: a morphologic study of cadaver larynges. Ann. Otol. Rhinol. Laryngol. 98:135-140.

Hunter L. 2011. Carnivores of the World. Princeton University Press, Princeton. 240p.

International Committee on Veterinary Gross Anatomical Nomenclature 2012. Nomina Anatomica Veterinaria. 5th ed. Editorial Committe, Knoxville. $177 \mathrm{p}$.

Kasper C.B., Trinca C.S., Sanfelice D., Mazim F.D. \& Trigo T.C. 2014. Os carnívoros, p.161-190. In: Gonçalves G.L., Quintela F.M. \& Freitas T.R.O. (Eds), Mamíferos do Rio Grande do Sul. Pacartes, Porto Alegre.

Kim M., Hunter E. \& Titze I. 2004. Comparison of human, canine, and ovine laryngeal dimensions. Ann. Otol. Rhinol. 113:60-68.

König H.E. \& Liebich H.G. 2011. Sistema respiratório, p.389-410. In: Ibid. (Eds), Anatomia dos Animais Domésticos: texto e atlas colorido. Artmed, Porto Alegre.

Larson J. 1993. Movement of the epiglottis in mammals. Dissertação de Mestrado em Odontologia, University of Washington, Washington. 33p.

Maue W. \& Dickson D. 1971. Cartilages and ligaments of the adult human larynx. Arch. Otolaryngol. 94:432-439.

Monteiro R. 2013. Correcção cirúrgica da paralisia da laringe em canídeos. Dissertação de Mestrado em Medicina Veterinária, Universidade Técnica de Lisboa, Lisboa. 70p.

Morel P. 1951. Les cartilages larynges du blaireau. Mammalia 15:47-49.

Morel P. \& Thiéry G. 1953. Sur le larynx des mustelides. Mammalia 17:187188.

Oliveira V., Souza A., Santos A.C., Bertassoli B.M., Rosa R.A., Carvalho A.F., Martins J.F.P. \& Mançanares C.A.F. 2011. Estudo morfológico do sistema respiratório de quati (Nasua nasua). Biotemas 25:81-92.

Pérez W., Lima M. \& Cuñarro B. 2006. Larynx anatomy in a tiger (Panthera tigris Linnaeus, 1758). J. Anim. Vet. Adv. 5:1093-1095.

Perard J. 1965. Comparative anatomy of the larynx of the dog and other carnivora. Can. Vet. J. 6:11-15.

Saigusa H. 2011. Comparative anatomy of the larynx and related structures. Japan Med. Assoc. J. 54:241-247.

Silva A.B.S., Santos T.M.V., Carvalho M.A.M., Guerra P.S.L., Rizzo M.S., Araújo W.R., Torres C.B.B. \& Conde Junior A.M. 2014. Morfologia da laringe de cutia (Dasyprocta sp.). Pesq. Vet. Bras. 34:593-598.

Silva E., Leite F., Souza T., Rossi Jr. J., Marchesi M. \& Alves D. 2010. Avaliação da Idade em Cachorros-Do-Mato, Cerdocyon thous (Linnaeus, 1758), por meio da mensuração do diâmetro do canal pulpar. Natureza Online 8:114-116.

Takada Y., Izumi M. \& Gotoh K. 2009. Comparative anatomy of the hyoid apparatus of carnivores. Mammal. Study 34:213-218.

Tayama N., Chan R.W., Kaga K. \& Titze I.R. 2001. Geometric characterization of the laryngeal cartilage framework for the purpose of biomechanical modeling. Ann. Otol. Rhinol. Laryngol. 110:1154-1161.

Tuohimaa P.T., Kallio S., Heinijoki J., Aitasalo K., Virolainen E., Karma P. \& Tuohimaa P.J. 1981. Androgen receptors in laryngeal carcinoma. Acta Oto-laryngologica 91:149-154.

Wysocki J., Kielska E., Charuta A., Janiuk I. \& Reymond J. 2008a. Analysis of measurements and proportion of young and adult individuals of domestic cattle. Electron. J. Polish Agric. Univ. 11:18.

Wysocki J., Kielska E., Orszulak P. \& Reymond J. 2008b. Measurements of pre- and postpubertal human larynx: a cadaver study. Surg. Radiol. Anat. 30:191-199.

Wysocki J., Kielska E., Janiuk I. \& Charuta A. 2010. Analysis of larynx measurements and proportions in young and adult domestic pigs (Sus scropha domestica). Turkish J. Vet. Anim. Sci. 34:339-347. 